The University of Maine

DigitalCommons@UMaine

Marine Sciences Faculty Scholarship

School of Marine Sciences

$1-1-1982$

\title{
Biological and Economic Effects of Increasing the Minimum Legal Size of American Lobster in Maine
}

James Acheson

University of Maine - Main, acheson@maine.edu

R. Reidman

Follow this and additional works at: https://digitalcommons.library.umaine.edu/sms_facpub

Part of the Agricultural and Resource Economics Commons, Aquaculture and Fisheries Commons, and the Social and Cultural Anthropology Commons

\section{Repository Citation}

Acheson, James and Reidman, R., "Biological and Economic Effects of Increasing the Minimum Legal Size of American Lobster in Maine" (1982). Marine Sciences Faculty Scholarship. 19.

https://digitalcommons.library.umaine.edu/sms_facpub/19 


\title{
TRANSACTIONS of the AMERICAN FISHERIES SOCIETY
}

January 1982

VOLUME 111

Transactions of the American Fisheries Society 111:1-12, 1982

(C) Copyright by the American Fisheries Society 1982

\section{Biological and Economic Effects of Increasing the Minimum Legal Size of American Lobster in Maine}

\author{
JAMES M. ACHESON \\ Department of Anthropology \\ Robert Reidman \\ Department of Economics \\ University of Maine, Orono, Maine 04469
}

\begin{abstract}
The Northeast Marine Fisheries Board recently completed a comprehensive management plan for American lobster Homarus americanus, the most important provision of which is to raise the legal minimum size of lobsters from 81 to $88.9 \mathrm{~mm}$ carapace length incrementally over 5 years. lts objective is to increase egg production and recruitment, and thus reduce the likelihood of stock failure; economic benefits are anticipated for fishermen. However, a model used to analyze the frequency distributions of some 9,000 Maine lobsters demonstrates that in every year the legal minimum size is increased, smaller numbers and less weight of lobsters would be landed than at present. After the legal measure reaches $88.9 \mathrm{~mm}$, there most likely still would be fewer lobsters harvested, but a $7.9 \%$ increase in landed weight due to increases in yield/recruit. An economic analysis by two-stage least-squares regression demonstrates that these changes in catches would result in a loss in total revenue to the Maine lobster industry in all 5 years the legal measure is increased. After it has reached $88.9 \mathrm{~mm}$, total revenue to lobster fishermen most likely would be $5.5 \%$ higher than it is now, a $13 \%$ internal rate of return on investment. These results suggest that increasing the legal lobster measure is problematic from the point of view of those in the industry.
\end{abstract}

This paper presents biological and economic data on the effect of raising the legal minimum carapace length of American lobster Homarus americanus from its current limit of $81 \mathrm{~mm}$ to a proposed limit of $88.9 \mathrm{~mm}$.

In the past 10 years, biologists, fisheries administrators, and fishermen have become increasingly concerned that the American lobster is being badly overexploited, and that there is a serious danger of imminent stock failure, which could lead to a drastic decline in catches and revenues for lobster fishermen and coastal communities. In the past several years, many different bills and recommendations for legislation have been drafted, including some dealing with limited entry and trap limits. Most of these bills have not passed. Several lobster biologists believe that one of the most effective kinds of conservation legislation would be to raise the minimum legal size of lobster from 81 $\mathrm{mm}$ to $88.9 \mathrm{~mm}$. Few recommendations make fishermen more anxious, or are likely to generate more political opposition, than this one.

The biologists point out that at least $90 \%$ of all lobsters are caught in the first year after they molt into the legal size, when they are between $81 \mathrm{~mm}$ and $92 \mathrm{~mm}$ (all sizes in this paper refer to carapace length). Only $6 \%$ of females are sexually mature at $81 \mathrm{~mm}$ (when they can be caught legally), whereas nearly all females are mature by the time they reach $98 \mathrm{~mm}$ at least 2 years later. Thus, biologists conclude that 
about $90 \%$ of female lobsters do not survive to extrude eggs. An increase in the legal measure to $88.9 \mathrm{~mm}$, they state, would ensure that at least $60 \%$ of female lobsters would have an opportunity to bear eggs at least once so that a very small increase in the legal measure would have a profound influence on the number of eggs released in the water, and ultimately on the long-run prospects for the industry itself.

Fishermen agree that a very large number of lobsters caught in Maine are just over the current legal size, and this is the source of their objection to raising the legal limit. They are afraid that an increase in the minimum measure to $88.9 \mathrm{~mm}$ would mean that a large percentage of the lobsters now caught would become illegal so that their incomes would be reduced drastically. In addition, they are worried that the larger lobsters resulting from an increase in the measure would be less marketable than the small, so-called "chicken" lobsters currently caught.

The biologists counter with the argument that they would not raise the legal minimum size to $88.9 \mathrm{~mm}$ in one step. That, they admit, would lead to severe revenue losses for most fishermen. Rather, they propose to raise the legal measure to $88.9 \mathrm{~mm}$ over the course of 5 years in $1.6-\mathrm{mm}$ annual increments. Such small increases, some believe, would minimize the reduction in catches and cause little economic hardship. In addition, they are certain that there is a good market for larger lobsters. Accordingly, a recommendation to increase the legal measure to $88.9 \mathrm{~mm}$ has been made a key feature of the Comprehensive Management Plan for American lobster recently produced by the Northeast Marine Fisheries Board (Anonymous 1978). ${ }^{1}$

Although political support for, or opposition to, this proposed management technique ultimately will depend on the effect it has on fishermen's income, neither the fishing industry

\footnotetext{
${ }^{1}$ Current regulations, and those recommended in the Management Plan, are couched in English measurement units. The proposal is to raise the minimum carapace length from its present $3^{3 / 16}$ inches to $3^{1 / 2}$ inches, in $1 / 16$-inch increments. Metric equivalents taken to $0.1 \mathrm{~mm}$, as they are in this paper, are unrealistic for field applications, but they help to emphasize that the annual size increments would be equal.
}

nor fisheries managers have useful estimates of the economic consequences that changes in the legal measure might have. In this paper, we will provide such estimates and discuss their implications for lobster management. First, we will present biological data in an attempt to project changes in the length-frequency distribution of lobsters in the catch, from which changes in harvest weights can be calculated. Second, we will present an economic model to determine the effect of changes in the legal lobster size on revenue received by fishermen.

The argument in this paper is based on the idea that fishermen are being asked to invest in the lobster industry. Current catches are being traded off for increased catches in the future. The key question is: Is this investment worthwhile economically? Specifically, the study demonstrates that fishermen would lose income in the 5 years the legal measure was being increased, and would gain in the subsequent years. It is not clear that benefits will outweigh costs.

\section{The Biological Model}

\section{Data Base}

Data were gathered as part of a general study of the lobster industry in the towns around Muscongus Bay on the central Maine coast. The data were gathered by six interviewers, who rode eighteen lobster boats during July and August 1977, November and December 1977, and April and May 1978. Every legal-sized lobster $(N=8,605)$ caught was measured with calipers.

James Thomas and his research crew from the Maine Department of Marine Resources also obtained size frequency distributions for lobsters from all over Maine from 1966 to 1977. In these years, he sampled 35,855 lobsters (J. C. Thomas, personal communication 1977). Despite the difference in the times the samples were collected, and the difference in sampling techniques, there are no important differences in the frequency distributions of lobster sizes reported by Thomas' research and our own. However, our sample turned up significantly more lobsters between $81 \mathrm{~mm}$ and $84 \mathrm{~mm}$ than are reported by Thomas. This difference does not cause any substantial change in the results produced by our model over the long run. The size frequency distributions confirmed a point that experienced fishermen make repeatedly- 
that a very high percentage of lobsters caught are just over the legal limit. Of all lobsters measured, $59 \%$ were under $88.9 \mathrm{~mm}$ (Table 1), and this much of the catch would be lost if the legal measure were increased from $81 \mathrm{~mm}$ to 88.9 $\mathrm{mm}$ in one year, which would put many fishermen out of business. The regulation actually being proposed is to increase the measure in much smaller increments for 5 years. Table 1 shows that in the first year, as the measure is increased from $81 \mathrm{~mm}$ to $82.6 \mathrm{~mm}$, the total number of lobsters caught will fall $11.7 \%$, but after that the table will support no reliable projections. To measure the incremental changes that will occur, changes in the frequency distributions in the catch need to be taken into account, along with several other factors such as natural mortality, trap selectivity, escapement from traps, annual rate of carapace growth, the proportion of female lobsters in each size category that are mature, and the proportion of mature females in each size category that are "berried" (egg-bearing). For the latter variables, we have used the estimates of experienced biologists.

\section{Natural Mortality}

There is a wide range of figures in the literature on annual average natural lobster mortality. At one extreme, there are estimates that only $2 \%$ of the lobsters will die if left in the water an extra year; other estimates range up to $30 \%$ (Thomas 1971). J. C. Thomas, who has had much experience in Maine, believes that the best estimate of annual average natural mortality is about $10 \%$ (personal communication 1980). We use this figure but its uncertainty must be stressed. Of the other eight published estimates, four are higher than $10 \%$ and four are lower (Anonymous 1978). Obviously, estimates of natural lobster mortality have high variance.

\section{Escapement}

According to Maine law, lobster traps must have a vent to allow small lobsters to escape. Thomas (1971) estimated that $90 \%$ of the lobsters between $81 \mathrm{~mm}$ and $82.6 \mathrm{~mm}$ escape, and about $10 \%$ of those between $82.6 \mathrm{~mm}$ and 84.1 $\mathrm{mm}$ do so as well. Our data suggest that very few 81-mm to 82.6-mm lobsters escape from traps at current vent sizes. In our model, we use Thomas' data on escapement for certain purposes and our own at other times.
TABLE 1.-Size-frequency distributions of American lobsters in commercial catches of Maine fishermen. The current legal minimum carapace length is $81.0 \mathrm{~mm} ; 88.9$ $\mathrm{mm}$ is a proposed minimum (highlighted by asterisks).

\begin{tabular}{cccccc}
\hline & \multicolumn{2}{c}{ This study } & & \multicolumn{2}{c}{ Thomas $^{\mathrm{a}}$} \\
\cline { 6 - 7 } \cline { 5 - 6 } $\begin{array}{c}\text { Carapace } \\
\text { length } \\
\text { (mm) }\end{array}$ & $N$ & $\begin{array}{c}\text { Cumula- } \\
\text { tive \% }\end{array}$ & & $N$ & $\begin{array}{c}\text { Cumula- } \\
\text { tive \% }\end{array}$ \\
\hline $81.0-82.6$ & 892 & 11.7 & & 1,853 & 5.2 \\
$82.6-84.1$ & 867 & 23.0 & & 3,918 & 16.1 \\
$84.1-85.7$ & 870 & 34.4 & & 4,609 & 28.9 \\
$85.7-87.3$ & 988 & 47.4 & & 4,150 & 40.5 \\
$87.3-88.9 *$ & $878^{*}$ & $58.9 *$ & & $4,103^{*}$ & $52.0^{*}$ \\
$88.9-90.4$ & 927 & 71.0 & & 4,108 & 63.4 \\
$90.4-92.0$ & 780 & 81.3 & & 3,458 & 73.1 \\
$92.0-93.6$ & 526 & 88.1 & & 2,980 & 81.4 \\
$93.6-95.2$ & 266 & 91.6 & & 2,741 & 89.0 \\
$95.2-96.8$ & 137 & 93.4 & & 1,270 & 92.6 \\
$96.8-98.4$ & 79 & 94.5 & & 733 & 94.6 \\
$98.4-100.0$ & 66 & 95.3 & & 936 & 95.5 \\
$100.0-101.6$ & 58 & 96.1 & & 272 & 96.3 \\
$101.6-103.1$ & 53 & 96.8 & & 219 & 96.9 \\
$103.1-104.7$ & 63 & 97.6 & & 219 & 97.5 \\
$104.7-106.3$ & 36 & 98.1 & & 183 & 98.0 \\
$106.3-107.9$ & 35 & 98.5 & & 130 & 98.4 \\
$107.9-109.5$ & 34 & 99.0 & & 113 & 98.7 \\
$>109.5$ & 78 & 100.0 & & 460 & 100.0 \\
\hline
\end{tabular}

${ }^{\text {a }}$ Unpublished data for 1966-1977, covering all of Maine.

\section{Growth Rate}

Virtually all lobster biologists agree that newly recruited lobsters in Maine waters grow about $14 \%$ in carapace length and increase $40-$ $50 \%$ in weight with every annual molt (Thomas 1971). In a cold year, molting of some lobsters might be retarded so that average annual growth might be $13 \%$. The range of growth rates used in our model is $13-15 \%$.

\section{Mature and Berried Females}

Some female lobsters will become sexually mature when they stay in the water for an extra year, and some of these will carry eggs, becoming illegal to catch. Both factors influence the weight of legally available lobsters. All percentages of mature and berried lobsters in any size class come from Krouse (1972) and Thomas (1971). Krouse has studied the proportion of mature females in each size class; Thomas' data indicate that an average $30 \%$ of sexually mature females are berried at any given time.

\section{Assumptions of the Model}

Five major assumptions underlie the biological model. 
(1) Recruitment into the fishery will not change during the years that the legal measure is being increased. In some years, as every fisherman knows, more small lobsters molt into legal size than in other years, but there is no way to predict such differences. More importantly, all serious attempts by biologists to demonstrate a positive relationship between number of eggs and recruitment have failed. As is stated in the lobster management plan (Anonymous 1978), "the relationship between parent stock, larval abundance, and subsequent catch is not known." There are no figures on probable increases in recruitment, nor even any range of estimates. Given this, it is most prudent to assume that there are no recruitment effects.

(2) Fishing effort will not change. Some fishermen may want to fish more traps as the measure is increased, and some may go out of business. Both factors will affect the fishing pressure put on the lobsters, but there is no way to predict what will happen.

(3) As the legal minimum size for lobsters increases, the legal vent size will be increased as well to reduce cannibalism, death from handling, et cetera. Specifically, it is assumed that the current vent size will remain in effect during the first 4 years that the measure is increased but will become larger in the fifth year. This will reduce the number of $88.9-\mathrm{mm}$ lobsters retained in traps.

(4) The average length $\left(L_{i}, \mathrm{~mm}\right)$ of lobsters in size class $i$ can be converted to average weight $\left(W_{i}, \mathrm{~g}\right)$ by 'Thomas' $(1971)$ formula:

$$
W_{i}=(0.001682) L_{i}^{2.82826} \text {. }
$$

(5) Our length-frequency distributions from Muscongus Bay are representative of the lobster population in Maine as a whole.

\section{Structure of the Biological Model}

The object of our biological modeI is to predict changes in the size and weight of lobsters in the catch as the legal minimum size is increased incrementally. The model operates by predicting two kinds of changes that occur. First, as the measure is increased, lobsters in that size range must be excluded from the available catch. At the same time, some of the lobsters that were excluded from the previous year's catch and survived are now available to be caught. These lobsters are fewer in number, but larger in weight. Some of these released lobsters are not available to be caught because they have died of natural causes or because they have become "berried." Second, we have developed formulas, applied to our sample, to calculate changes in the catch in the entire state.

It is important to note that in the first year, as the measure is increased from 81 to 82.6 $\mathrm{mm}$, the number of variables the model takes into account is small. In later years, all of the variables we have discussed influence size and weight distributions in complicated ways.

The biological model used in this paper was modified from equations used by Hancock (1975) and Gulland (1961), who analyzed the effects of changes in mesh size on catches of crabs in England and herring in northern Europe, respectively.

Let the sample of lobsters collected on the boats be described by the carapace length-frequency distribution $N_{i}, i=1, \ldots, k$, where $N_{i}$ is the number of lobsters in the $i$ th size category. With this notation, $i=1$ is the $81-82.6$ $\mathrm{mm}$ category, $i=2$ is the $82.6-84.1-\mathrm{mm}$ category, and so on down the list in Table 1. This is the base-year frequency distribution, sampled with the legal measure set at $81 \mathrm{~mm}$.

We assume, given the large size of the sample, that the length-frequency distribution of the total Maine lobster catch is directly proportional to $N_{i}$ by a constant $b$, which is the ratio of the total number of lobsters caught on the coast to those in our sample. In the base year (the year before the first incremental increase is made), the total catch $C$ of lobsters in numbers is

$$
C(0)=b \sum_{i=1}^{k} N_{i}
$$

Let $C(t), t=1, \ldots, 6$ represent the numerical catch for years 1 through 6 . Starting in year 1 and ending in year 5 , the minimum legal lobster size will be increased by $1.6 \mathrm{~mm}$ annually.

In year 1 , size interval 1 becomes illegal, so

$$
C(1)=b \sum_{i=2}^{k} \frac{S_{i}(1)}{S_{i}(0)} N_{1},
$$

where $S_{i}(0)$ is the base-year trap selectivity for the $i$ th size group; that is, the base-year probability that a trap will retain a lobster of size $i$. Similarly, $S_{i}(1)$ is the trap selectivity size $i$ in year 1.

In the second year, a proportion of the $N_{i}$ lobsters released the year before will have 
grown to legal size. The catch in year 2 is

$$
\begin{aligned}
C(2)= & b \sum_{i=3}^{k} \frac{S_{i}(2)}{S_{i}(0)} N_{i} \\
& +b \sum_{j=1}^{k} \frac{S_{j}(2)}{S_{j}(0)}(1-M) q_{i j}\left(1-p_{j}\right) N_{i},
\end{aligned}
$$

where $S_{j}(2)$ is trap selectivity for the $j$ th size group in year $2, M$ is the average annual rate of natural mortality, $p_{\mathrm{j}}$ is the proportion of all lobsters in the $j$ th size category that can be expected to be bearing eggs, and $q_{i j}$ is the proportion of lobsters that were in the first size category in the previous year, but have grown into the $j$ th size category in the current year.

The expression after the second summation represents the number of lobsters that, having been released into the fishery in year 1 , have survived and been caught in year 2 . This number will be less than $b N_{i}$ because trap selectivity is different for these new larger lobsters, some will have died, and some will have become berried.

The formula assumes that $100 \%$ of the lobsters released in year 1 and not affected by these three factors will be caught in year 2 .

In the third year, the catch will be

$$
\begin{aligned}
C(3)= & b \sum_{i=4}^{k} \frac{S_{i}(3)}{S_{i}(0)} N_{i} \\
& +b \sum_{i=1}^{2} \sum_{j=1}^{k} \frac{S_{j}(3)}{S_{j}(0)}(1-M) q_{i j}\left(1-p_{j}\right) N_{i},
\end{aligned}
$$

where $q_{i j}$ now represents the proportion of lobsters that have grown from size $i$ in year 2 to size $j$ in year 3 . The values of the $q_{i j}$ s depend upon the annual rate of carapace growth.

In general, for any arbitrary year $t$, the catch can be represented as

$$
\begin{aligned}
& C(t)=b \sum_{i=r}^{k} \frac{S_{i}(t)}{S_{i}(0)} N_{i} \\
& \quad+b \sum_{i=1}^{y} \sum_{j=1}^{k} \frac{S_{j}(t)}{S_{i}(0)}(1-M) q_{i j}\left(1-p_{j}\right) N_{i} ; \\
& x=\operatorname{Min}(t, 5) ; \quad y=\operatorname{Min}\{[\operatorname{Max}(0, t-1)], 5\} .
\end{aligned}
$$

Carapace lengths are converted to lobster weights by 'Thomas' (1971) formula

$$
\begin{aligned}
Q_{t}= & b \sum_{i=x}^{k} \frac{S_{i}(t)}{S_{i}(0)} N_{i} W_{i} \\
& +b \sum_{i=1}^{y} \sum_{j=1}^{k} \frac{S_{j}(t)}{S_{i}(0)}\left(1-p_{j}\right) N_{i} W_{i},
\end{aligned}
$$

where $x$ and $y$ are defined as above.
Finally, percent changes from base-year numbers and weights are

$$
C(t)^{*}=100[C(t)-C(0)] / C(0) .
$$

If either fishing effort or lobster recruitment change from their base-year levels, the equations for total catch will be difficult to interpret. The formulae for the percentage change in catch remain valid, but instead of the change from the base-year catch, they represent the change from what the catch would have been, had the measure remained at $81 \mathrm{~mm}$. This distinction will prove important when the biological model is integrated with the economic model to predict changes in lobster industry revenue.

\section{Results of the Biological Model}

We generated three sets of results from the model. First, we used figures for natural mortality, growth rate, escapement, and berried females that we consider reasonably accurate, and produced what we call the "most-likely" results. A range of estimates exists for some of the variables used. Because it is possible (but highly unlikely) that some of the extreme observations or estimates are accurate, we next used figures on all variables that would maximize the lobster catch after the minimum legal measure reaches $88.9 \mathrm{~mm}$. This we call the "best case." Last, we calculated the "worst case," using values that would minimize the lobster catch at the end of 6 years. It must be stressed that the best and worst cases are highly unlikely to materialize, but they are useful for purposes of discussion and because they set limits on the problem.

\section{Likely Results}

In estimating the most likely results, we have used $10 \%$ for annual natural mortality and $14 \%$ for annual carapace growth. We have taken Krouse's (1972) size distribution of mature females, and assumed that $30 \%$ of all released, mature females will be berried when caught. We started with our own length-frequency data and assumed, as they suggest, that there is no significant escapement.

Results indicate that in each of the 5 years the measure is increased, there will be a decrease in the number and total weight of lobsters caught (Table 2). In the sixth year, after the measure has reached $88.9 \mathrm{~mm}$, there will be a loss of $12.0 \%$ in numbers, but a $7.9 \%$ in- 
TABLE 2.-Most-likely, best-possible, and worst-possible changes in Maine landings of American lobster if the legal minimum carapace length is raised incrementally over 5 years.

\begin{tabular}{|c|c|c|c|c|c|c|c|}
\hline \multirow[b]{3}{*}{ Year } & \multirow{3}{*}{$\begin{array}{l}\text { Change in } \\
\text { minimum } \\
\text { carapace } \\
\text { length }(\mathrm{mm})\end{array}$} & \multicolumn{6}{|c|}{$\%$ change from current landings } \\
\hline & & \multicolumn{2}{|c|}{ Most-likely results } & \multicolumn{2}{|c|}{ Best-case } & \multicolumn{2}{|c|}{ Worst-case } \\
\hline & & Numbers & Weight & Numbers & Weight & Numbers & Weight \\
\hline 1 & 81.0 to 82.6 & -11.7 & -9.2 & -11.7 & -9.2 & -11.7 & -9.2 \\
\hline 2 & 82.6 to 84.1 & -13.5 & -7.7 & -12.8 & -6.7 & -15.2 & -9.9 \\
\hline 3 & 84.1 to 85.7 & -15.7 & -6.7 & -14.4 & -4.6 & -19.0 & -11.1 \\
\hline 4 & 85.7 to 87.3 & -19.6 & -7.1 & -14.8 & -0.2 & -22.7 & -11.5 \\
\hline 5 & 87.3 to 88.9 & -20.9 & -4.7 & -27.3 & -8.7 & -37.8 & -24.2 \\
\hline 6 & Remains at 88.9 & -12.0 & +7.9 & -7.8 & +20.4 & -22.9 & -9.0 \\
\hline
\end{tabular}

crease in weight over base-year values. There would be no additional gains expected in the seventh, eighth, or ninth years.

As the measure is increased from $81 \mathrm{~mm}$ to $88.9 \mathrm{~mm}$, the number of egg-bearing females will double. Although these females cannot be legally caught, they undoubtedly will increase the number of eggs in the water. In the far future, this might augment recruitment to the fishery but, as noted above, there is no factual basis for such a projection.

\section{Best-Case Results}

In estimating the best-case results, we assumed that annual average natural mortality is only $4.6 \%$, one of the lowest published figures (Thomas 1971). We let carapace length increase by $15 \%$ per year. We decreased all Krouse's (1972) data for numbers of mature females by $10 \%$, and assumed only $27 \%$ will be berried to inflate allowable catch. We accepted Thomas' unpublished (1979) estimates that a high proportion of the smallest legal lobsters escape from traps and survive to be caught in future years, but used our own data on size frequencies.

As is shown in Table 2, in this best case both numbers and weight of lobsters caught by fishermen will drop during every year the measure is increased. In the sixth year, however, there would be a $20.4 \%$ increase in the total weight of the catch due to the larger size of the lobsters being caught.

\section{Worst-Case Results}

We took worst-case mortality to be $24.2 \%$, a figure that has been suggested (Thomas 1971), and growth rate to be only $13 \%$ per year. We increased all Krouse's (1972) data on numbers of mature females by $10 \%$ and assumed that $33 \%$ will be berried when caught. We used Thomas' data on escapement. Again we used our own data on length frequencies.

Not surprisingly, under worst-case conditions both the numbers of lobsters and the weight caught will decline every year the legal measure changes (Table 2). Most importantly, there will be a permanent $22.9 \%$ decline in numbers and a permanent $3.0 \%$ reduction in the total landed weight.

In summary, our model indicates there will be a drop in both numbers of lobsters caught and the landed weight as the Iegal measure increases. In the best and most-likely cases, after the measure has reached $88.9 \mathrm{~mm}$ the numbers of lobsters caught will be less than in the base year. There will be, however, an increase in weight, most likely $7.9 \%$. Whether this will result in an increase or a decrease in income for fishermen depends, as we shall see, on the elasticity of demand.

\section{The Economic Model}

Revenue to fishermen is the quantity of lobsters caught times their ex-vessel price. To assess changes in revenue as the legal lobster measure is increased from 81 to $88.9 \mathrm{~mm}$, we need to know the change in the quantity of lobsters caught and the price associated with that change.

In the previous section, we saw that landings will fall every year the measure increases. The income of fishermen might drop with them, but it might increase if the price of lobsters increases with a reduction in catch.

In this section, we will develop a model to link landings with revenue. This economic model is derived in two stages. First, we develop 
simple supply and demand equations to obtain information on the way the price of lobster changes as the quantity of lobster varies in the market. (This has nothing to do with changes in the legal measure.) Second, we transform our supply and demand equations to an expression that will accept the data from the biological model to predict changes in revenue.

\section{Supply and Demand}

We have used a two-stage least-squares regression technique to estimate coefficients in the demand and supply equations for lobsters (Wonnacott and Wonnacott 1981). We first derived a list of factors likely to influence lobster demand and supply, based on economic theory and observations of the lobster fishery. These factors were used in the estimation of a supplyand-demand model of the market for lobsters between 1947 and 1978. In estimating the equations for lobster, we used only one simplifying assumption: that there were no price/size effects; that is, that the price per kilogram did not vary with the size of the lobster. (This assumption will be discussed below.)

\section{Supply}

The supply of lobsters depends in the first place on water temperature, because temperature affects activity levels, shedding, and natural mortality, as well as the predilection of lobsters to crawl into traps (Dow 1969). In addition, the quantity of lobsters landed depends on the willingness of fishermen to fish for them. This is influenced by the price of other species that fishermen might hunt as well as by the weather. For these reasons, the variables we used in estimating the supply equation were the ex-vessel prices of cod Gaddus spp., scallops Placopecten magellanecus, yellowtail flounder $\mathrm{Li}$ manda ferrugina, haddock Melanogrammus aeglefinus, and shrimp Pandalus borealis, which were obtained from the Maine State Landings Bulletins. In addition, we used variables on the annual average seawater temperature and numbers of days per year snow exceeds $2.5 \mathrm{~cm}$. These latter figures were obtained from the Maine Department of Marine Resources and the United States Weather Service.

With these variables, our two-stage leastsquares technique turned up a very surprising result-the price elasticity of supply is very low (estimated at 0.18 in 1977). That the supply of lobsters is so highly inelastic probably indicates that fishermen are taking all the lobsters they can possibly take now. Increases in the price may motivate men to fish harder, but will not increase the catch.

In economic theory, changes in price are determined by both demand and supply curves. Because the supply curve for lobster is highly inelastic, all changes in price are due primarily to changes in demand. Accordingly, we have ignored the supply-side effect completely in estimating a model for lobster. All social scientists studying the economics of the lobster industry have done the same.

\section{Demand}

Other factors influence the quantity of any good that consumers purchase besides the price of the good itself. The most important of these are consumers' incomes and the prices of substitutable goods. In our demand equation for lobster, we included information on national income, obtained from Survey of Current Business, Bureau of Economic Analysis, United States Department of Commerce. Data on price and quantity of most fish species came from Maine State Landings Bulletins, although some of the data were derived from Fishery Statistics of the United States (United States Department of Commerce), and the ICNAF Statistical Bulletins (International Commission for the Northwest Atlantic Fisheries). Data on other food products that might be substituted for lobster, such as beef, pork, or lamb, generally were derived from Agricultural Statistics, United States Department of Agriculture. Price of lobster in the United States is influenced by imported Canadian lobsters as well as by demand. Data on imports were obtained from ICNAF.

When our two-stage least-squares technique was run on these variables, only five significantly influenced the demand for lobster (Table 3). The most significant is the price of lobster, and our figures indicate that as the ex-vessel price of lobster increases 2.2 cents per kilogram, the amount demanded falls by about $263,537 \mathrm{~kg}$ in the United States as a whole. (For 1978 , we estimate the price elasticity of demand is -1.292 , and the income elasticity of demand is 0.86.) National income is next in degree of importance; if it increases by one billion dollars, the increase in the quantity of lobster demanded will be $20,865 \mathrm{~kg}$. Increasing prices of scal- 
TABLE 3.-Estimated lobster demand equation in the United States: 1947-1978.

\begin{tabular}{lccc}
\hline \multicolumn{1}{c}{ Variable } & $\begin{array}{c}\text { Regression } \\
\text { coefficient }\end{array}$ & $\begin{array}{c}\text { Signif- } \\
\text { icance }\end{array}$ & $\begin{array}{c}\text { Symbol } \\
\text { in } \\
\text { equation }\end{array}$ \\
\hline Lobster price & -0.5808 & 0.0001 & $b_{1}$ \\
National income & 0.0459 & 0.0001 & $b_{2}$ \\
Price of scallops & 0.0732 & 0.005 & $b_{3}$ \\
Price of clams & 0.1402 & 0.005 & $b_{4}$ \\
Price of rock lobster & & & \\
$\quad$ tails & 0.0121 & 0.1 & $b_{5}$ \\
Constant & 49.3412 & & $a$ \\
$R^{2}=0.73$; adjusted $R^{2}=0.66$ & &
\end{tabular}

${ }^{a}$ All prices are expressed in cents per kilogram; national income is billions of dollars.

${ }^{\mathrm{b}}$ Halibut, beef, pork and chicken were examined but all proved to be insignificant $(P>0.1)$.

lops, clams, and imported rock lobster tails, substitute goods, also raise the demand for lobsters. None of the meat products were significant, probably because a high percentage of fish and meat is consumed in specialized restaurants whose patrons do not substitute meat for fish or vice versa.

\section{Modified Demand Equation}

The biological model provides estimates of relative changes in future Maine lobster landings, $Q(t)^{*}$, due to the phased implementation of the $88.9-\mathrm{mm}$ minimum legal lobster size. To evaluate the economic impact of these changes, we first must convert the predicted quantity of landings into predicted ex-vessel price and then into estimated changes in future Maine lobster industry revenues. For this purpose we have estimated a lobster demand equation and then modified it in a series of steps to accept Maine data on lobster landings from our biological model. The steps in this modification process are outlined below.

The demand equation which shows the relationship between the quantity of lobsters purchased, the level of national income, and the prices of certain seafoods that are substitutes for lobsters, can be represented as

$$
\begin{aligned}
& M E Q(t)+U S Q(t)+C I Q(t)= \\
& \quad a+b_{1} L O(t)+b_{2} N I(t)+b_{3} S C(t)+b_{4} C L(t) \\
& \quad+b_{5} R T(t) .
\end{aligned}
$$

Here, $M E Q, U S Q$, and $C I Q$ are quantities of American lobster landed in Maine, landed elsewhere in the United States, and imported from
Canada, respectively; $t$ indicates year; $L O, S C$, $C L$, and $R T$ are the prices of lobster (ex-vessel), scallops, clams, and rock lobster tails, respectively, in constant (inflation-corrected) dollars; $N I$ is national income, and $a, b_{1}, \ldots, b_{5}$ are the regression coefficients given in Table 3 . In the demand equation dollar values were corrected to 1967 dollars, but results of the economic model are reported in 1978 dollars to facilitate comparison with current dollars.

\section{Revenues to Lobstermen}

To project revenues, the demand equation is solved for lobster price $L O(t)$; the revenue $R(t)$ to Maine lobstermen is price times Maine landings:

$$
R(t)=L O(t) M E Q(t)
$$

or, because $M E Q(t)$ is the same as $Q(t)$ from the biological model,

$$
R(t)=L O(t) Q(t)
$$

The annual gain, or loss, in Maine lobster revenue that results from the phased change in the minimum legal carapace length is

$$
\Delta R(t)=R(t)-R(0),
$$

where $R(0)$ is base-year revenue measured before the carapace regulation is changed. The percent change in revenue $R(t)^{*}$ is

$$
\begin{aligned}
R(t)^{*}= & 100 \Delta R(t) / R(0) \\
& =100[R(t)-R(0)] / R(0) .
\end{aligned}
$$

Because we are interested only in the effect on revenue caused by changes in legal minimum lobster size, we have fixed all the variables except lobster price and Maine landings at their $1977(t=0)$ levels. These are $U S Q=14.38 \times$ $10^{6} \mathrm{~kg}, C I Q=6.55 \times 10^{6} \mathrm{~kg}, N I=\$ 834.88 \times$ $10^{9}, S C=\$ 2.32 / \mathrm{kg}, C L=\$ 1.44 / \mathrm{kg}$, and $R T=$ $\$ 6.53 / \mathrm{kg}$.

Finally, to determine whether or not the proposed change in legal measure is of economic benefit to the industry, we must obtain the internal rate of return for the changes in revenues that will occur as the measure is increased incrementally. This we calculated by a standard equation (Weston and Brigham 1975), which must be solved for $r$, the internal rate of return:

$$
\sum_{i=1}^{20} \frac{\Delta R(t)}{(1+r)^{t}}=0
$$

Although the predicted changes in revenues 


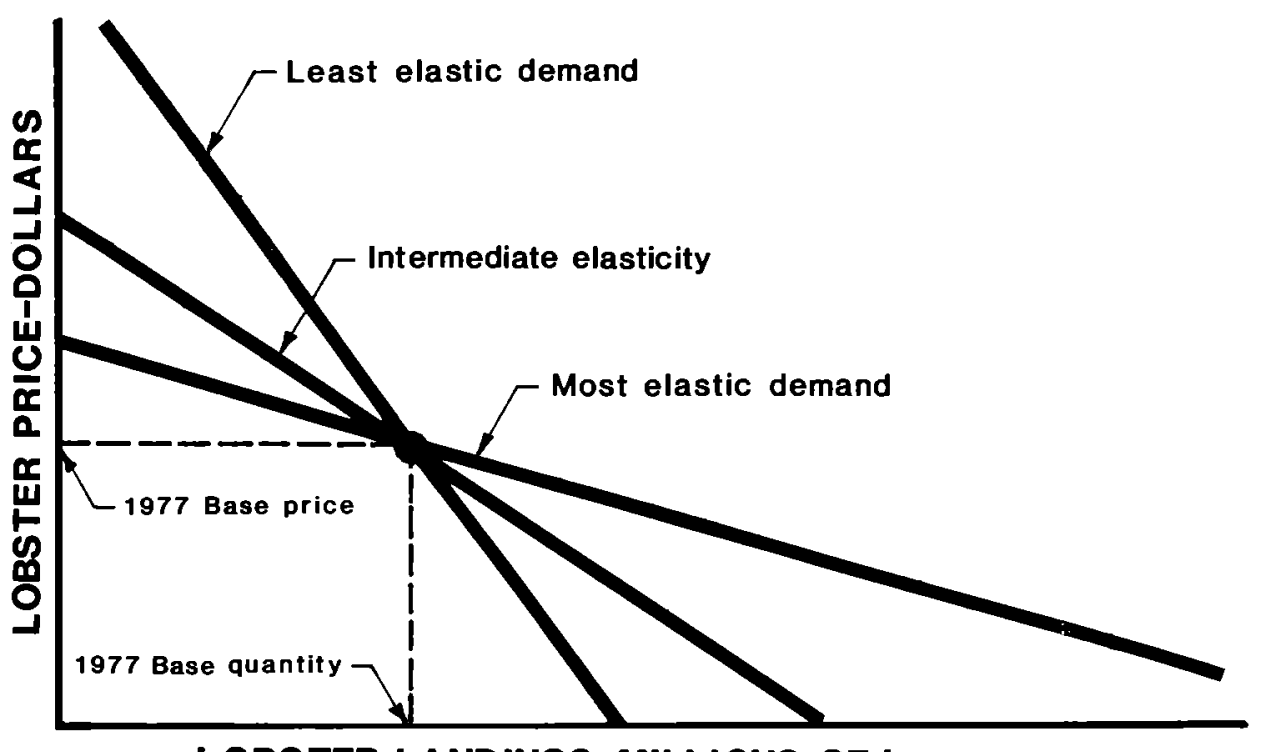

\section{LOBS TER LANDINGS-MILLIONS OF $\mathbf{k g}$}

FIGURE 1.-General relationships between ex-vessel prices for American lobster and quantity of landings under three conditions of demand elasticity.

are evaluated for only the first 20 years, extending the time horizon beyond 20 years will not significantly increase the internal rate of return.

In order to determine how sensitive the revenue predictions are to statistical error, we used three different estimates for the lobster price coefficient in the demand equation. First, we calculated revenues to fishermen using a lobster price coefficient $\left(b_{1}=-0.5805\right)$ that came directly from our estimated demand equation $(-1.292)$. Then we calculated revenues using higher and lower price coefficients that represent greater or lesser, respectively, elasticities of demand. These higher and lower figures were obtained by estimating the range of possible variation on the original price coefficient. Thus, we have used three different demand equations (curves) to estimate the relationship between quantity of lobsters landed and their price (Fig. $1)$.

\section{Results of the Economic Model}

To calculate changes in revenues to fishermen as the legal carapace measure changes, we used the economic model (which takes output from the biological model) to calculate nine sets of results: the best, worst, and most-likely bio- logical cases in combination with relatively more elastic, relatively less elastic, and intermediately elastic demand curves.

The most-likely changes in revenue are projected by the combination of "most-likely" landings with intermediate demand elasticity. These projections (Table 4) indicate that there will be a loss in total revenue to the lobster industry in all 5 years that the carapace measure is increased-from $\$ 2.43$ million in the first year to $\$ 1.22$ million in the fifth. In the sixth year, after the measure has reached $88.9 \mathrm{~mm}$, there will be a permanent gain of $\$ 1.95$ million $(5.5 \%)$ to Maine lobstermen, which will occur every year thereafter. These are estimates of gains and losses to the fishery as a whole, and they do not predict what income to any given fisherman might be.

Similar results (not shown) came from the other eight combinations of landings and demand curves. Every projection shows a loss of revenue to lobster fishermen every year the measure is increased. The magnitude of the loss varies with the combination, of course. The most optimistic results are produced by the best-case biological model coupled with least elastic demand. Under these conditions, there would be an average annual loss to the lobster 
TABLE 4.-Changes in revenue to fishermen as the legal lobster measure is increased from $81 \mathrm{~mm}$ to $88.9 \mathrm{~mm}$.

\begin{tabular}{|c|c|c|c|c|c|c|}
\hline Year $^{a}$ & $\begin{array}{l}\text { Legal } \\
\text { mea- } \\
\text { sure } \\
(\mathrm{mm})\end{array}$ & $\begin{array}{l}\text { Land- } \\
\text { ings }{ }^{\mathrm{b}} \\
\left(10^{6} \mathrm{~kg}\right)\end{array}$ & $\begin{array}{l}\text { Price }^{\mathrm{c}} \\
(\$ / \mathrm{kg})\end{array}$ & $\begin{array}{l}\text { Reve- } \\
\text { nued } \\
\left(10^{6} \$\right)\end{array}$ & $\begin{array}{c}\text { Revenue } \\
\text { change } \\
\left(10^{6} \$\right)\end{array}$ & $\begin{array}{c}\text { Percent } \\
\text { change } \\
(\%)\end{array}$ \\
\hline 1 & 82.6 & 7.61 & 4.31 & 32.82 & -2.43 & -6.885 \\
\hline 2 & 84.1 & 7.71 & 4.29 & 32.23 & -2.02 & -5.730 \\
\hline 3 & 85.7 & 7.82 & 4.28 & 93.50 & -1.75 & -4.968 \\
\hline 4 & 87.3 & 7.76 & 4.28 & 33.39 & -1.86 & -5.272 \\
\hline 5 & 88.9 & 7.99 & 4.25 & 34.03 & -1.22 & -3.459 \\
\hline 6 & 88.9 & 9.04 & 4.11 & 37.20 & +1.95 & +5.538 \\
\hline
\end{tabular}

a Year indicates the number of years after the start of the incremental increase in the lobster measure.

${ }^{b}$ Landings in 1977 , our baseline year, were $8.34 \times 10^{6} \mathrm{~kg}$.

c Prices have been adjusted to 1978 baseline levels. In 1977 the base price was $\$ 4.12 /$ kilogram.

d Revenue (landings $\times$ price) is expressed in millions of 1978 dollars.

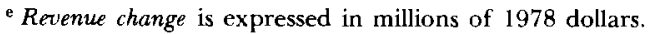
(These results have been corrected for inflation.)

industry of only $0.6 \%$ during the 5 years the measure is increased, and a $19.8 \%$ gain in revenue in the sixth year. The most pessimistic result (worst-case biological results with most elastic demand) indicates an average loss of $14.8 \%$ during each of the first 5 years, and a permanent annual loss of $8 \%$ thereafter. It must be stressed that we consider extreme results to be outlandish because the values used are most unlikely to occur.

\section{Advisability of Increasing the Minimum Legal Measure for Lobsters}

Is it worthwhile to increase the minimum legal measure for lobsters? The fishermen currently in the industry will answer differently from society as a whole. We will begin with the viewpoint of fishermen and then discuss the broader implications.

When we increase the legal measure, we are asking fishermen to sacrifice current revenues to gain a permanent increase in revenues in the future. We are, in essence, asking them to invest in the future of the industry. The critical question then becomes: Is the rate of return on that investment large enough to compensate fishermen for the short-run losses in revenues? The standard method for assessing an investment when the costs and revenues extend over a period of years is to calculate the internal rate of return. These rates vary for the nine combinations of landings and demand elasticities
TABLE 5.-Annual internal rates of return a to Maine lobster fishermen if minimum legal carapace lengths are increased from 81.0 to $88.9 \mathrm{~mm}$, projected by combinations of biological and economic models.

\begin{tabular}{lrrc}
\hline & \multicolumn{3}{c}{ Biological model } \\
\cline { 2 - 4 } \multicolumn{1}{c}{ Economic model } & \multicolumn{3}{c}{ Most- } \\
\hline Most elastic demand & $4 \%$ & $0 \%$ & $0 \%$ \\
lntermediate elasticity & $4 \%$ & $19 \%$ & $0 \%$ \\
Least elastic demand & $70 \%$ & $49 \%$ & $0 \%$ \\
\hline
\end{tabular}

a Internal rates of return were calculated over 20 years for constant 1978 dollars.

(Table 5). As we saw (Table 4), under the most likely revenue projections, fishermen will sacrifice an average $5.3 \%$ of their current revenues in each of the 5 years the carapace measure is increased, and will gain $5.5 \%$ every year after the measure reaches $88.9 \mathrm{~mm}$. For this most likely outcome, the return on the lobster fishermen's investment as the measure is increased is $13 \%$ (Table 5 , center cell).

We ran the same model, with the same specifications, using Thomas' size-frequency data in place of our own. Again, the most likely estimate of internal rate of return was $13 \%$. Our data indicate more small lobsters than Thomas observed; with our figures in the model, economic losses are greater in the first years the measure is increased, but smaller in later years, and the long-term gain is slightly greater. These differences balance out, so that the same internal rate of return is produced by both Thomas' data and our own.

The most pessimistic result is generated by worst-case biological data combined with most elastic demand: $0 \%$ internal rate of return (Table 5). Should these extreme assumptions prove accurate, fishermen would not only lose in the first 5 years, but would suffer additional losses in every subsequent year. The most optimistic results-from best-case biological data with least elastic demand-give an internal rate of return of $70 \%$. Under these conditions, fishermen would receive back not only the original investment they made as the measure was being increased in the first 5 years, but $70 \%$ more in every subsequent year. Again, we regard these most optimistic and most pessimistic results as wholly unrealistic.

According to our best estimate, fishermen will get a $13 \%$ return on the financial sacrifice 
they make during the 5 years of change in the legal measure. Return on investment in growing industries in the United States was only $10-$ $12 \%$ during 1979, and this is considered good. Given these figures, fishermen probably would be rational to support an increase in the carapace measure. Two important caveats should be added. First, there is no guarantee they would receive $13 \%$; some of our data are uncertain enough that smaller or larger returns might materialize. Second, the inevitable shortterm sacrifice will be borne by fishermen now in the business, some of whom may not be around to reap the long-term benefits; the benefits will accrue, in part, to newcomers. Thus, to individual lobstermen, the financial merits of a change in minimum legal carapace length may appear dubious.

From the point of view of the state of Maine as a whole, one can make a stronger case for increasing the measure. Our data indicate that an increase in the measure likely will bring some increase in revenues in the future. We are not certain which fishermen will gain the benefits but we know that fishermen in aggregate will gain financially over the long run.

In addition, an increase in the measure probably will double the number of egg-bearing females. Given the uncertainty of the stock-recruitment relationship, we do not know if this will result in higher catches in the future, but it will add a margin of security that some biologists feel is necessary if a drastic decline in the lobster population is to be averted (Anonymous 1978).

\section{Research to Improve the Model}

In the course of doing this research, we discovered that the precision of our model is limited chiefly by two things. First, it is very sensitive to estimates of natural mortality. As noted previously, estimates of natural mortality vary from $4 \%$ to $30 \%$. Although most biologists agree that it is about $10 \%$, firmer estimates with confidence intervals would help narrow the range of our biological estimates. Second, the precision could be increased if economic data were available in monthly rather than annual time units. The lack of monthly data probably has caused us to overestimate somewhat the economic benefits of increasing the carapace measure.

A third important area for future concern is the size-price relationship. Students of fisheries economics have noted that differential prices are paid for fish of different size, and they are beginning to take size into account in estimating demand for fish (Gates 1974). Such size effects exist in the lobster industry. In the Boothbay, Maine area, particularly, a premium price is charged for prime "dinner" lobsters. "Chicken" lobsters and larger lobsters bring a lower price per unit weight. In our model we have ignored this issue. We recognize that a change in the carapace measure will alter these size-price effects because it will change size distributions in the catch, but we do not know exactly how. An increase in the measure will bring a greater yield of "dinner" lobsters $(0.55-0.67 \mathrm{~kg})$, which now bring a higher price. If the price holds, there might be increased revenues to the industry, but price could drop if enough lobsters of this size are harvested. On the other hand, an increase in the measure will result in fewer small lobsters; these scarce "chicken" lobsters might bring the highest price per unit weight if there is a group of consumers or restaurant owners that prefers them. Available data support no prediction about the effect lobster size will have on industry revenues as the measure is increased.

Last, but not least, the need for further research on recruitment is very obvious. Additional factors could have caused us to overestimate internal rates of return. Gauges used by fishermen for measuring lobsters would have to be changed repeatedly, and an increase in the vent size would mean that millions of traps would have to be altered. In addition, there will be costs in administration, education, and enforcement. We have ignored these costs, due to the problems of estimation involved. However, our model would have been improved had some way of including them been devised.

\section{Acknowledgments}

The data in this paper were collected during a project entitled "University of Rhode IslandUniversity of Maine Study of Social and Cultural Aspects of Fisheries Management in New England under Extended Jurisdiction," supported by the National Science Foundation, Grant AER-77-06018. The authors wish to thank John Thorvaldson, William Acheson, Jayne Lello, John Bort, and Terry Cucci who collected many of the data, and the 18 lobster 
fishermen from Pemaquid Harbor, New Harbor, Bremen, and Friendship for their generous support and cooperation. Special thanks are due to Ann Acheson who edited and proofread several drafts of the article.

\section{References}

ANonymous. 1978. American lobster fishery management plan. Northeast Marine Fisheries Board, Gloucester, Massachusetts, USA.

Dow, R. L. 1969. Cyclic and geographic trends in seawater temperature and abundance of American lobster. Science (Washington, District of Columbia) 164:1060-1063.

Gates, J. 1974. Demand price, fish size and the price of fish. Canadian Journal of Agricultural Economics 27(3): 1-12.

Gulland, J. A. 1961. The estimation of the effect on catches of changes in gear selectivity. Journal du Conseil, Conseil International pour l'Exploration de la Mer 26:204-214.
Hancock, D. A. 1975. The Yorkshore fishery for edible crabs (Cancer pagurus): assessment of the effect of changes in the minimum legal size. Fishery Investigations, Series 11, Marine Fisheries Great Britain Ministry of Agriculture Fisheries and Food 27(8).

Krouse, J. S. 1972. Size at first sexual maturity for male and female lobsters found along the Maine coast. Lobster Information Leaflet 2. Maine Department of Sea and Shore Fisheries, Augusta, Maine, USA.

ThomAs, J. C. 1971. An analysis of the commercial lobster (Homarus americanus) fishery along the coast of Maine, August 1966-September 1970. Maine Department of Sea and Shore Fisheries, Augusta, Maine, USA.

Weston, J. F., AND E. F. Brigham. 1975. Managerial finance, 5th edition. Dryden Press, Hinsdale, Illinois, USA.

WONNACOTt, T. M., AND R. T. WONNACOTT. 1981. Regression: a second course in statistics. John Wiley and Sons, New York, New York, USA. 